\title{
Recensão do livro "Casa e Mudança Social: uma leitura das transformações de sociedade portuguesa a partir da casa" ${ }^{1 "}$
}

\author{
Maria Assunção Gato², DINÂMIA’CET-IUL, Portugal
}

O recente livro de Sandra Marques Pereira - Casa e Mudança Social - resulta do rigoroso trabalho de investigação que a autora desenvolveu no âmbito da sua tese de doutoramento em Sociologia. Não deixando de ser uma obra de cariz académico, a sua leitura é acessível e passível de cativar um público bastante diversificado, desde estudiosos provenientes das várias ciências sociais e humanas aos técnicos e outros profissionais ligados aos espaços urbanos, à habitação e aos mercados imobiliários. Acresce ao interesse particular da obra o facto de ela trazer à luz dimensões do habitar em contexto português que, de alguma forma, foram permanecendo ocultas, não obstante a sua relevância no âmbito das transformações socioculturais das últimas décadas.

É um facto que o espaço casa tem vindo a conquistar cada vez mais importância na sociedade portuguesa, quer enquanto objecto de consumo e de cultura material, quer enquanto elemento identitário, de vivência e de representação social, quer ainda enquanto "cenário" simbólico envolvendo pessoas e coisas em modos de ser e habitar de elevada complexidade. Num contexto internacional têm surgido vários trabalhos, sobretudo de cariz antropológico, que vêm consolidando um corpo teórico em torno do espaço doméstico e sua cultura material (Cieraad, 1999; Carsten e Hugh-Jones, 1999; Hearn e Roseneil, 1999; Wilk, 2001; Csikszentmihalyi e RochbergHalton, 2002; Miller, 2001, 2008, 2010). Daí a relevância de trabalhos como este também em Portugal, que numa perspectiva dialogante entre dimensões sociais, estruturais e culturais, vão revelando perspectivas contemporâneas de entendimento sobre a casa e, mais especificamente, sobre modos de habitar de novas classes médias urbanas.

O objecto central desta obra de investigação é o fogo ou a casa, entendida simultaneamente enquanto componente fundamental da cultura material de qualquer sociedade e enquanto território privilegiado das expressões identitárias e vivenciais de quem nela habita. O percurso realizado em torno de tão complexo objecto é formalizado através do seguinte ponto de partida: "até que ponto é que o espaço doméstico corporiza as mudanças que caracterizam a sociedade portuguesa ao longo do tempo e de que forma algumas das mudanças sociais que marcam a actualidade são vividas pelos seus protagonistas através da casa?” (Pereira, 2012:2). Desvendando já a resposta a esta dupla questão conclui a autora que as actuais formas de habitar praticadas pelos indivíduos apresentam-se muito mais heterogéneas e complexas do que as casas oferecidas pelo mercado, onde a evolução ao longo do tempo se fez de um modo homogéneo e linear.

Se a transformação da casa não é, tal como reconhece a autora, um assunto "simples" de tratar - na medida em que implica várias transformações sobrepostas e a diferentes ritmos - perceber as transformações da sociedade portuguesa através da casa afigura-se, de facto, num projecto bastante ambicioso, ainda que focado num segmento muito específico da sociedade portuguesa - a nova classe média urbana residente em Lisboa.

Estruturalmente e com vista a alcançar tal objectivo, esta obra encontra-se organizada em nove capítulos, distribuídos por três partes. A primeira parte, que enquadra também o capítulo inicial, introduz a problemática central desta investigação através de uma discussão sociológica entre a casa e a mudança social. Para esta discussão são convocadas não só as dimensões culturais e sociais da casa enquanto espaço construído e vivido, mas também duas variáveis consideradas importantes para compreender algumas mudanças sociais

\footnotetext{
${ }^{1}$ Pereira, S.M. (2012), Casa e Mudança Socialidade em Transição. Nobilitação Urbana. Estilos de Vida e Reurbanização em Lisboa, Lisboa: Caleidoscópio.

2 maria.gato@iscte.pt
} 
contemporâneas: a classe social, como enquadramento para as novas classes médias e a família, pelo seu natural protagonismo relativamente ao espaço doméstico.

A segunda parte é inteiramente dedicada a um ensaio diacrónico focado essencialmente sobre os significados sociológicos das morfologias habitacionais burguesas da Lisboa do século XX. Trata-se de uma análise exploratória que vai confrontando modelos habitacionais de referência da arquitectura urbana praticada em Lisboa - gaioleiro, Estado Novo ou português suave e a casa de matriz moderna - com os respectivos contextos (temporais, sociais, políticos e culturais), através de uma gradação de escalas espaciais que vai da casa, do edifício e do bairro até ao enquadramento urbano associado a cada um dos modelos.

Por fim, a parte três é composta pelos estudos de caso, focalizados nos três modelos habitacionais diferenciados (e também diferenciadores) que marcam a contemporaneidade, na cidade de Lisboa, em termos de oferta imobiliária socialmente dirigida - os lofts, os studios residence e a arquitectura sustentável. Um dos objectivos centrais desta parte é a compreensão dos significados sociológicos que motivam uma procura habitacional marcada pela diferenciação. Para além da ligação óbvia desta questão aos estilos de vida das novas classes médias urbanas (conotados com individualizações pós-modernistas e respectivos consumos distintivos), existe também a confrontação com um mercado imobiliário que há muito se caracteriza por uma oferta demasiado homogeneizadora e pouco criativa.

Através de uma análise sincrónica, os três modelos habitacionais constituem-se enquanto casos de estudo individualizados e no âmbito dos quais são exploradas três dimensões fundamentais inerentes à casa: a sua estrutura, os seus habitantes e a forma como estes habitam e se apropriam do espaço doméstico. A apresentação dos três estudos de caso é ainda complementada por comparações analíticas entre eles. Tais comparações não só permitem à autora explorar componentes menos visíveis das formas de habitar, como possibilitam ao leitor uma percepção mais abrangente e comprometida com os propósitos de demonstrar algumas das mudanças sociais através das formas de produzir, viver e representar as casas.

Não pretendendo conseguir um retrato socialmente representativo das formas de habitar (e também de Ser) das novas classes médias residentes em Lisboa, a autora visa, através desta obra, aprofundar o conhecimento sobre certos protagonistas dos recentes processos de recomposição social do Portugal contemporâneo, cujo desempenho modernizador é passível de antecipar algumas dinâmicas relevantes na reconfiguração dos espaços urbanos e na reestruturação dos modos de habitar (Pereira, 2012: 137).

Não obstante o determinismo social e a previsibilidade inerente a algumas dessas dinâmicas, esta obra pode servir como referência para o estudo de outros fragmentos sociais igualmente importantes na reconfiguração dos espaços urbanos do Portugal contemporâneo, contribuindo assim para o enriquecimento de novas perspectivas de análise sobre os espaços domésticos, bem como para a abertura a outras realidades sociais e respectivas formas de habitar.

\section{BIBLIOGRAFIA}

Carsten, J., Hugh-Jones, S. (Eds.) (1999), About the House, Cambridge: Cambridge University Press.

Cieraad, I. (Ed.) (1999), At Home: An anthropology of domestic space, New York: Syracuse University Press.

Csikszentmihalyi, M., Rochberg-Halton, E. (2002), The Meaning of Things: domestic symbols and the self, Cambridge: Cambridge University Press.

Hearn, J., Roseneil, S. (Eds.) (1999), Consuming Cultures: Power and resistance, Great Britain: MacMillan Press.

Miller, D. (Ed.) (2001), Home Possessions. Material Culture Behind Closed Doors, Oxford: Berg.

Miller, D. (2008), The Comfort of Things, Cambridge: Polity Press. 
Miller, D. (2010), Stuff, Cambridge: Polity Press.

Pereira, S.M. (2012), Casa e Mudança Social: Uma leitura das transformações da sociedade portuguesa a partir da casa, Vale de Cambra: Caleidoscópio.

Wilk, R. (2001), "Houses as consumer goods: Social processes and allocation decisions", in D. Miller (Ed.), Consumption: Critical concepts in the social sciences, Vol.III, London: Routledge. 